\title{
SCRATCH-PROFILES STUDY IN THIN FILMS USING SEM AND EDS ${ }^{\dagger}$
}

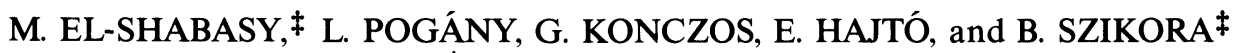 \\ ${ }^{\ddagger}$ Technical University, Budapest \\ Central Research Institute for Physics, Budapest, Hungary \\ (Received November 1, 1982; in final form July 6, 1983)
}

\begin{abstract}
The adhesion of evaporated or sputtered thin films to substrates is one of the most important characterising parameters in their fabrication. It is a conventional method to scratch the films using a stylus and evaluate the shearing stress, which is proportional to the energy of adhesion. For the evaluation it is necessary to determine the so-called critical load and the profile of the scratch.

The aim during this experimental work was to find a method to evaluate the scratch profile from the X-rayline profile and SEM pictures. From SEM pictures, the lateral dimensions and surface morphology of the scratches were studied. The thickness was also studied from X-ray-line profiles.

In this paper the thickness profile measuring method and the conclusion for the scratch method are discussed.
\end{abstract}

\section{INTRODUCTION}

The adhesion of thin films to their substrates and to one another has been one of the most important parameters in all thin film technology. Mittal ${ }^{1}$ has recently reviewed comprehensively the adhesion measurement techniques for thin films. The well known scratch method has been shown to yield and hold some promise as a quantitative test under certain conditions. The scratch test consist of drawing a smoothly rounded tip of known radius, $\mathrm{R}$, across the film surface and a vertical load, $\mathrm{W}$, applied to the point, is gradually increased until the film is removed from the substrate forming clear track. The amount of load on the tip at film failure which is known as the critical load is related to the shearing force caused by film failure by a simple formula derived by Benjamin and Weaver. ${ }^{2}$ So, that adhesion could be calculated as a shearing force, F:

where $\quad F=\frac{A P}{\sqrt{R^{2}-A^{2}}}, A=\sqrt{\frac{W}{\pi P}}$

where $\mathbf{A}$ is the radius of the circle of contact, $\mathbf{P}$ is the indentation hardness of the substrate material.

In the present work, the scratch test coupled with SEM and EDS has been used to study and discuss the scratch profiles were also studied and used to evaluate the adhesion strengths of thin films.

\section{EXPERIMENTAL PROCEDURE}

The scratch apparatus used in this work is provided with a microprocessor controlled

\footnotetext{
${ }^{\dagger}$ Paper originally presented at the 5th International Spring Seminar on Electrotechnology held at Prenet, Czechoslovakia, 1-4 June, 1982.
} 
$(x-y)$ stage $^{3}$ on which the test specimen was attached. The substrate bearing the film under test was mounted under the stylus on the stage which could be moved horizontally in two directions using programmed tape. The motorized $\mathrm{x}$-movement drives the stylus from right to left to make the scratch. Following the movement the stylus is unloaded by raising it off the substrate. The scratch is then inspected by transmitted light using an optical microscope to detect film failure. The stylus is brought down into contact with the specimen with a known force so that its vertical position is adjusted to scratch the specimen.

The load was then incremently increased, and the test was repeated on an adjacent area. A series of scratches has been made at successively higher loads until failure, an illuminated scratch path is observed in either the film or the substrate.

Vacuum deposition from directly heated and from electron-bombardment heated sources was used for $\mathrm{Cu}$ and $\mathrm{Mn}$. A steady deposition rate was obtained before opening a shutter to expose the substrate.

Variation of film thickness could be obtained subsequent to initial substrate exposure by partial reinterposition of the shutter. The substrates used were of Corning glass 7059 cleaned by chemical solvents and also by glow discharge cleaning before film deposition.

The measurement was performed with a JSM-35 JEOL scanning electron microscope equipped with a PGT-1000 energy dispersive spectrometer. The electron beam diameter was about $15 \mathrm{~nm}$ with a beam current of $300 \mathrm{pA}$. The electron beam was scanned across the scratch perpendicularly. The scanning time was $15 \mathrm{~s}$ and it was repeated 100 times in each measurement. The lateral resolution was measured on a chemical etched calibration pattern, its value was $0,4 \mu \mathrm{m}$ on $300 \mathrm{~nm} \mathrm{Mn}$ sample. The real lateral resolution was better, ${ }^{4}$ since the etched pattern was not exactly perpendicular step profile.

\section{RESULTS AND DISCUSSION}

Figure 1 shows a plot of the calibration curves of the $\mathrm{CuK}_{\alpha}$ and $\mathrm{MnK}_{\alpha} \mathrm{X}$-ray emission

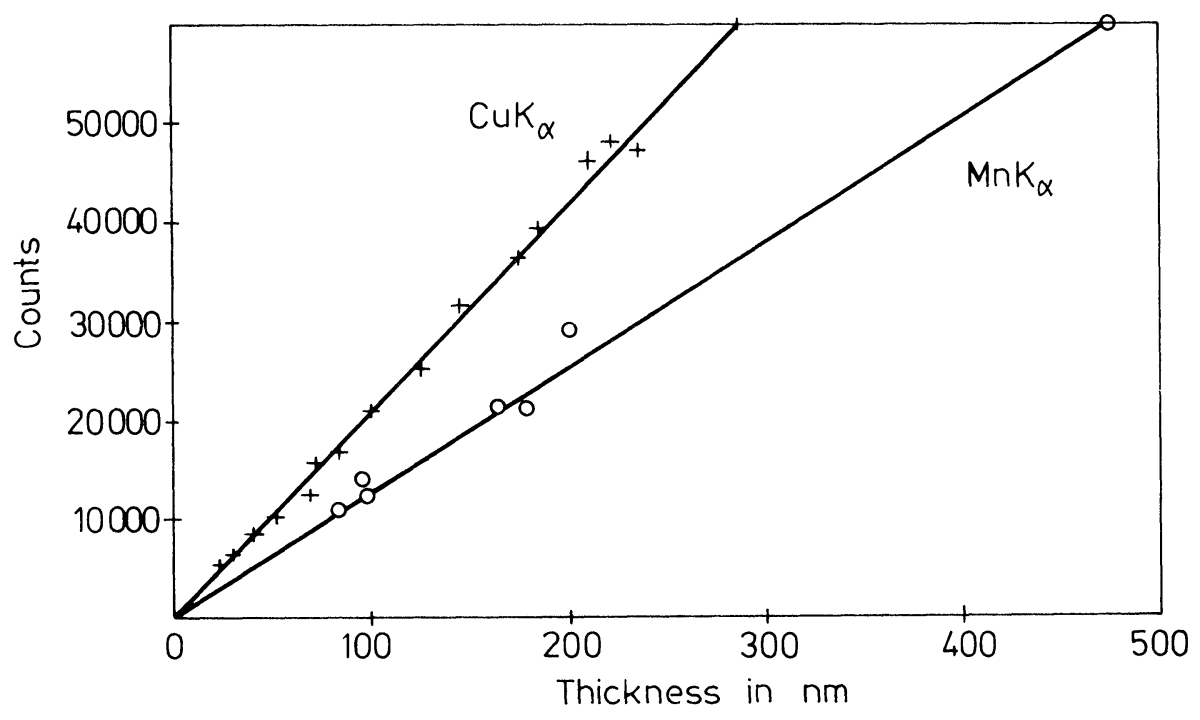

FIGURE 1 Calibration curves. 


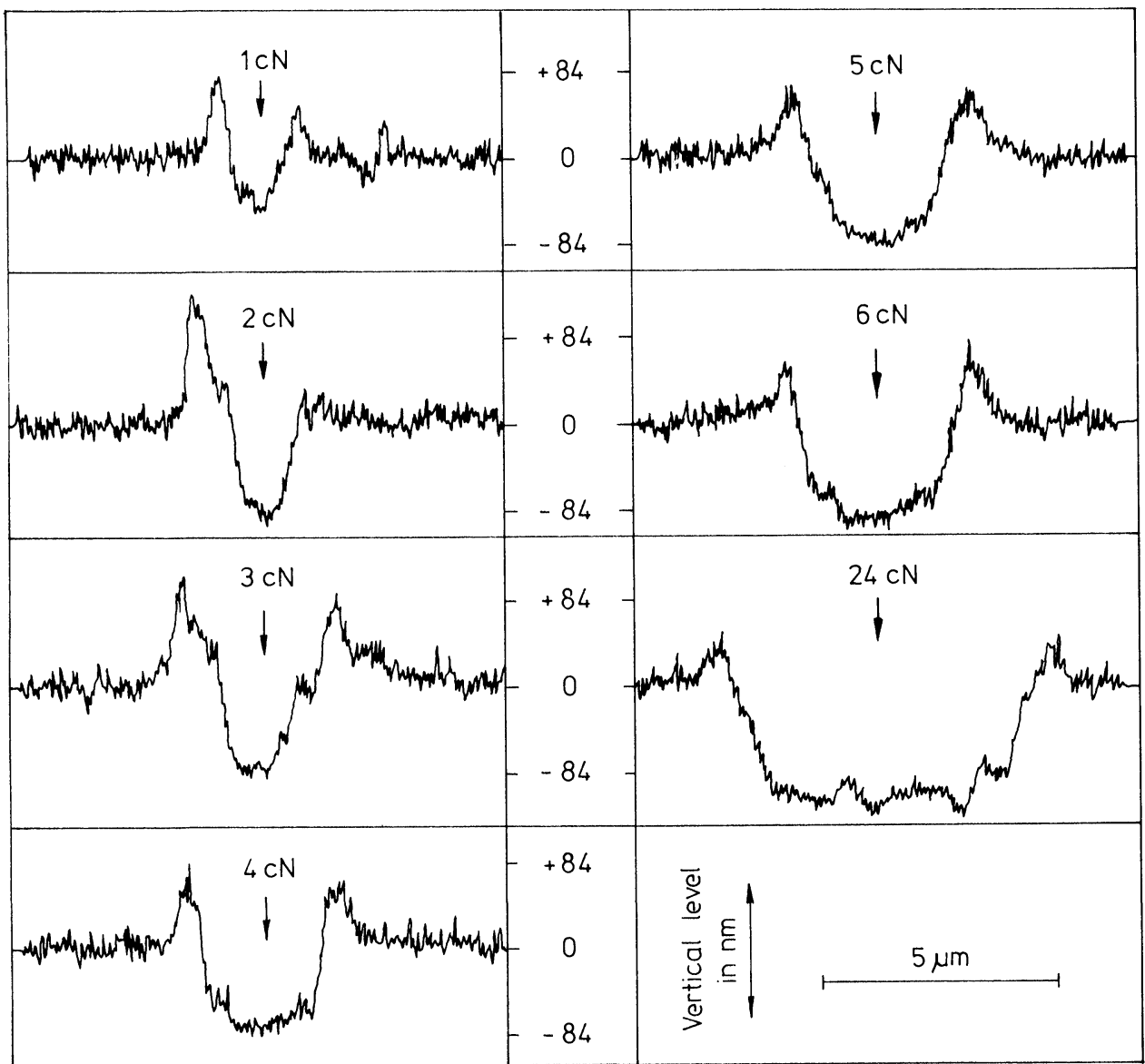

FIGURE 2 Scratch profiles in $\mathrm{Cu}(84 \mathrm{~nm})$ layer.

intensities against the various thicknesses of both $\mathrm{Cu}$ and $\mathrm{Mn}$ layers. As can be seen, the intensities show a linear resolution to thickness at accelerating voltage of $20 \mathrm{kV}$.

Critical loads were first determined by optical and after that by scanning electron microscopy. The results were performed on selected sample of $\mathrm{Cu}$ layer of thickness $84 \mathrm{~nm}$. A series of 24 scratch lines were made in the $\mathrm{Cu}$ film and each scratch was made with a different normal load within the range of $1-24 \mathrm{cN}$ respectively. An electron beam of diameter $15 \mathrm{~nm}$ was used to excite the $\mathrm{x}$-radiation, since the electron beam is scanned across the scratches perpendicularly. Using SEM and EDS, the profiles of the scratches could be estimated. Figure 2 shows the estimated profiles of the scratches number $1 . . .6$ and the last scratch number 24 at loads $1 . .6$ and $24 \mathrm{cN}$ respectively. From these profiles the depth can be recorded accurately. The measured depth are plotted against the applied loads shown in Figure 3. The results show that the depth was not increased above a definite value of the load say, $2 \mathrm{cN}$, since the layer completely removed from the substrate. The critical load as detected by EDS was found to be $2 \mathrm{cN}$ while the critical load as detected by optical microscope was found to be $4 \mathrm{cN}$. So far, the EDS and SEM was found to be a more accurate technique for measuring the depth of the profiles.

Figure 3 shows also the variation between the width of the tracks against the applied load. It has been observed that the width of channels gradually increased with the 


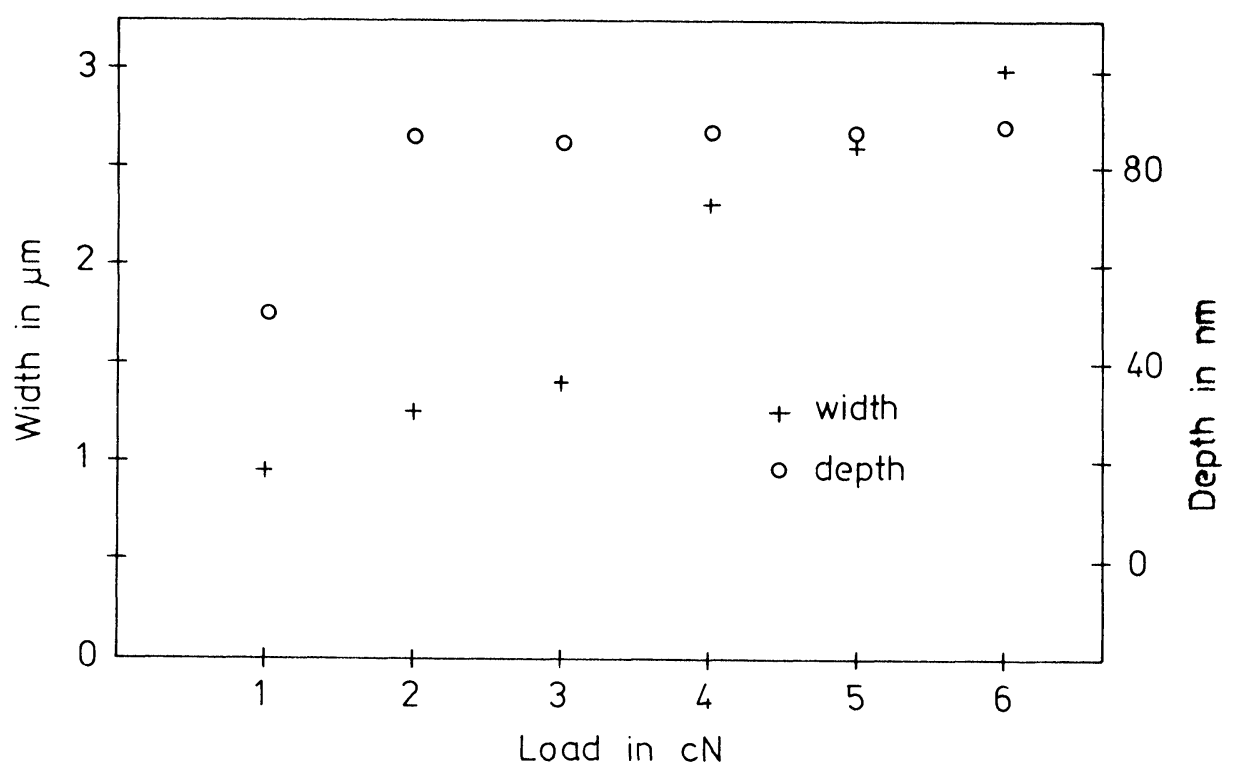

FIGURE 3 Changing of depth and width in scratched $\mathrm{Cu}(84 \mathrm{~nm})$ layer.

applied load. At $4 \mathrm{cN}$ there was a wide change in the width of the channels. The shear stress at the critical load observed both by SEM coupled with EDS and optical microscope was $78 \times 10^{7} \mathrm{~Pa}$ and $56 \times 10^{7} \mathrm{~Pa}$ respectively.

Figure 4 shows the detected profiles of $\mathrm{Mn}$ layer at $32 \mathrm{cN}$ and $62 \mathrm{cN}$. As can be seen

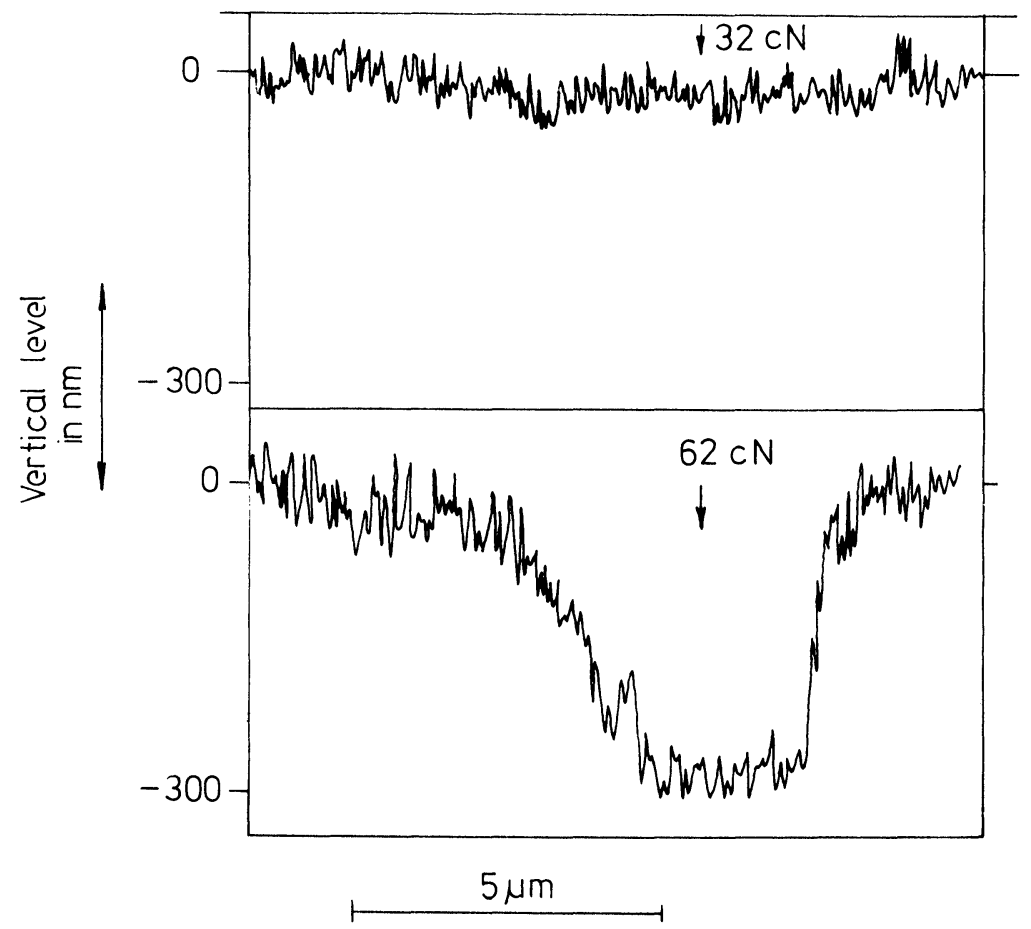

FIGURE 4 Scratch profiles in Mn (300 $\mathrm{nm})$ layer. 
that there was no dent at $32 \mathrm{cN}$, but at higher load say, $62 \mathrm{cN}$ the layer was removed suddenly from the substrate. This was attributed to the brittleness of Mn layer.

\section{CONCLUSIONS}

1. The mechanism of film removal and the depth of the measured profiles depends on whether the film is soft or brittle.

2. For measuring the scratching profiles as detected by SEM and EDS, it seems to be that these techniques are more accurate and suitable for detecting the clear channels.

Knowing the real profile of the scratches, there will be a possibility of developing a model of the scratch process which incorporates the effect of plastic and elastic deformation of both the layer, and substrate as well as the function.

\section{REFERENCES}

1. K.L. Mittal, Elect. Sci. and Tech. 321 (1976).

2. P. Benjamin and C. Weaver, Pro. Roy. Soc. 254A 163 (1960)

3. S. Fülöp, Gy. Laczházi, Finommechanika-Mikrotechnika 20, 323 (1981).

4. L. Pogány, G. Konczos, É. Hajtó, M. El-Shabasy, B. Szikora, XII. Magyar Elektromikroszkópos és Mikroanalizis Konferencia, Eger, (1982). 

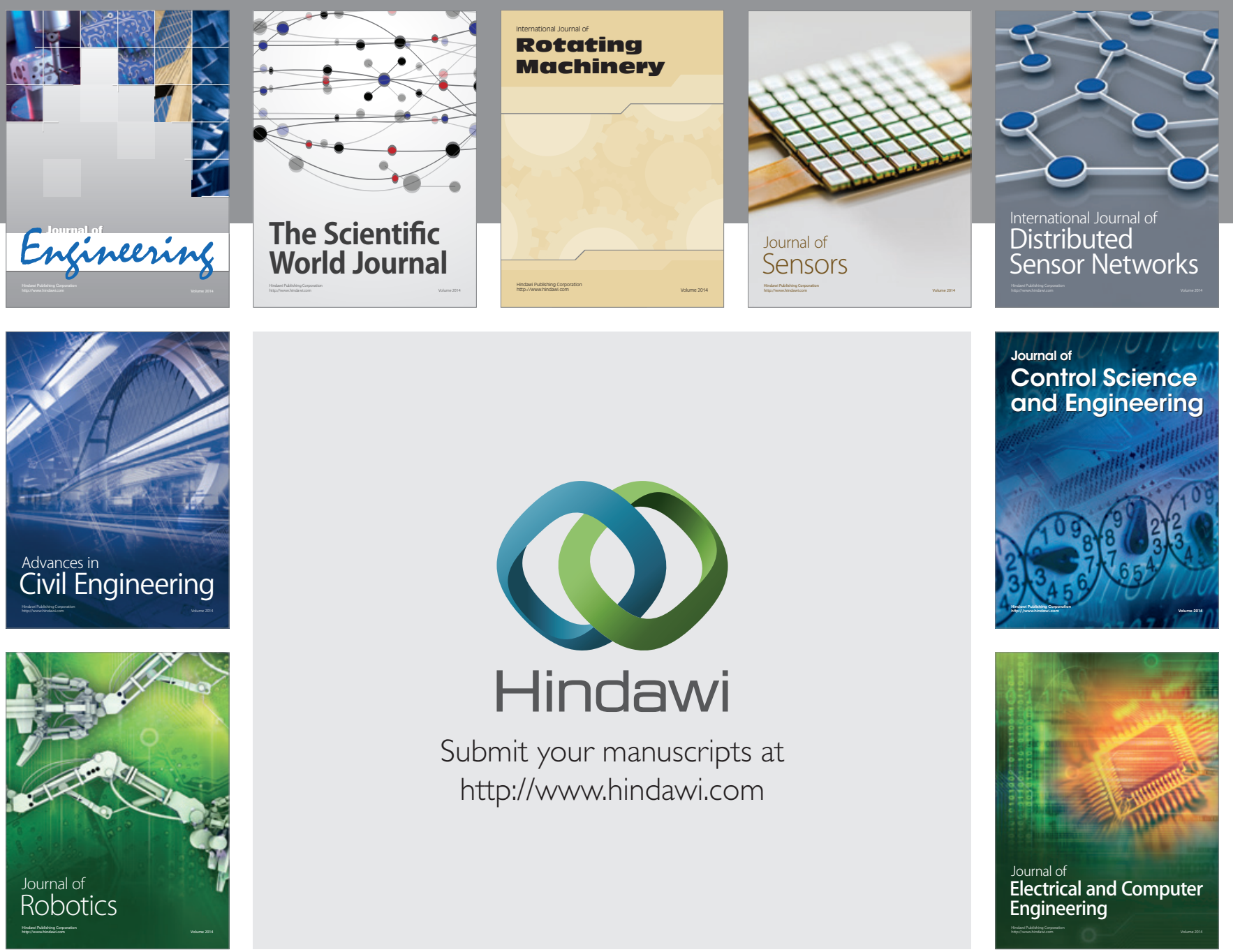

Submit your manuscripts at

http://www.hindawi.com
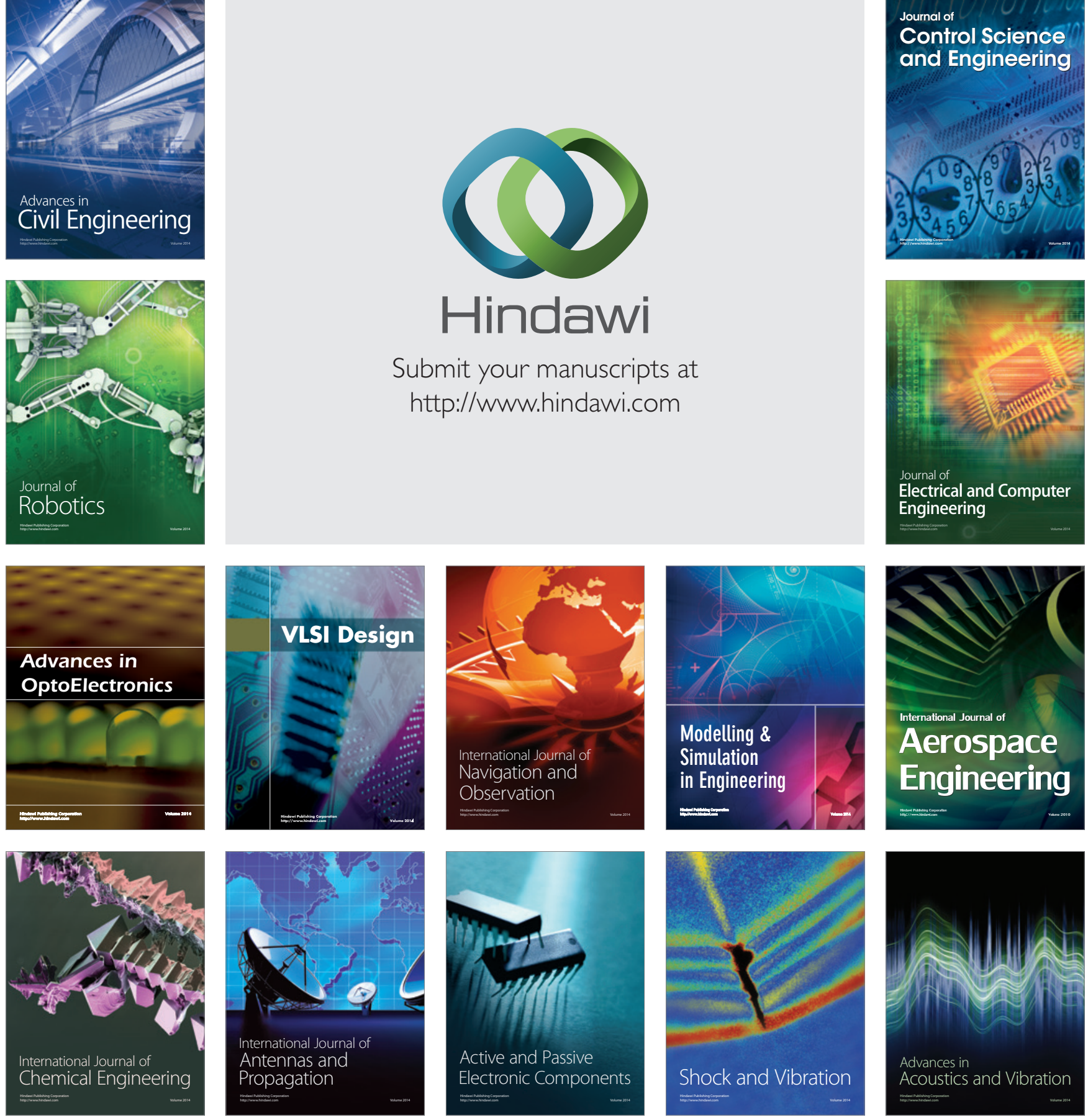